\title{
Macroalgae as Lead Trapping Agents in Industrial Effluents - A Factorial Design Analysis
}

\section{Marta M. M. B. Duarte ${ }^{a}$, José E. da Silva ${ }^{b}$, José Z. de O. Passavante ${ }^{c}$, M. Fernanda Pimentel ${ }^{d}$, Benício de Barros Neto ${ }^{b}$ and Valdinete L. da Silva ${ }^{*}$}

${ }^{\mathrm{a}}$ Fundação Instituto Tecnológico do Estado de Pernambuco - ITEP. Av. Prof. Luiz Freire, 700, Cidade Universitária, 50740-540, Recife - PE, Brazil

${ }^{\mathrm{b}}$ Departamento de Química Fundamental, Universidade Federal de Pernambuco, Av. Prof. Luiz Freire, s/n, Cidade Universitária, 50740-250, Recife - PE, Brazil

${ }^{\mathrm{c}}$ Departamento de Oceanografia, Universidade Federal de Pernambuco, Campus Universitário, 50670-901, Recife - PE, Brazil

${ }^{\mathrm{d}}$ Departamento de Engenharia Química, Universidade Federal de Pernambuco, Rua Teresa Melia, s/n, Cidade Universitária, 50670-901, Recife - PE, Brazil

\begin{abstract}
Um planejamento fatorial de dois níveis foi empregado para analisar a influência da agitação, do tempo de contato, da quantidade de alga e do tipo de pré-tratamento sobre a remoção de metais pesados por algas Arribadas, num sistema em batelada contendo uma solução sintética simulando um efluente típico de fabricação de baterias. Amostras de $4 \mathrm{~g}$ de algas secas, moídas e peneiradas removeram $99 \%$ do chumbo de amostras de $100 \mathrm{~mL}$ do efluente sintético. Os percentuais máximos de remoção de zinco e ferro foram $37 \%$ e $80 \%$, respectivamente. Como as algas arribadas são baratas, abundantes e de ocorrência natural, a remoção de chumbo através deste método pode ser vantajosa para aplicação industrial em larga escala.
\end{abstract}

A two-level factorial design was employed to analyze the influence of agitation, contact time, amount of algae and type of pretreatment on heavy metal removal by Arribadas algae, in a batch system consisting of a synthetic solution simulating a typical effluent from battery manufacturing processes. Dried, ground and sieved $4 \mathrm{~g}$ algae samples were able to remove $99 \%$ lead from $100 \mathrm{~mL}$ samples of synthetic effluent. Maximum removals for zinc and iron were $37 \%$ and $80 \%$, respectively. Lead removal using this method is potentially useful for large-scale industrial applications, because Arribadas algae are cheap, abundant, naturally occurring waste materials.

Keywords: factorial design, algae, lead, zinc, iron

\section{Introduction}

One of the undesirable consequences of increasing industrial activity is the increase in metal concentrations in natural water sources, caused by the large output of industrial effluents contaminated with heavy metals ${ }^{1}$. Removing from solution metallic species dispersed in natural environments is thus a matter of great practical interest, either because these species are highly toxic (mercury, lead, cadmium, zinc, nickel and chromium, for example) or because they have high aggregate value (gold, silver, and platinum).

Lead is a heavy metal occurring in effluents from battery manufacturing processes. It is an element with no known

\footnotetext{
*e-mail:vlins@npd.ufpe.br
}

biological function. It is also highly toxic to living beings, even at low concentrations, because, like other heavy metals, it inhibits many enzyme-catalyzed biochemical reactions. Therefore, industrial plants that use lead as a raw material need efficient methods to reduce to a safe level the concentration of this metal in their effluents.

The traditional methods commonly employed to remove heavy metals from effluents, such as chemical precipitation, oxidation/reduction, filtration, electrochemical processes, adsorption by activated carbon or ion-exchange resins, are not always convenient. In some cases either they are not effective enough, or their cost is prohibitive, especially when the metals are present in low concentrations (1-100 $\left.\mathrm{mg} \mathrm{L}^{-1}\right)$ in large bodies of water ${ }^{2}$.

In the last few years, increasingly stronger pressures from society at large and from environmental protection agencies 
have pushed forward the development of alternative methods of pollution fighting. This in turn has led to a growing interest in the use of biological organisms for trapping heavy metals. These technologies are less aggressive to the environment and also economically promising but, in spite of much research effort, few biosorption processes have reached commercial application. One possible reason is that, in order to be accepted by the engineering community, a new metal ion biosorption process must be economically competitive ${ }^{3}$.

A number of researchers have investigated the feasibility of using cheaply available marine or fresh water algae for heavy metal removal ${ }^{3-8}$. However, these studies employed algae of a single isolated species, and to extend their results to large-scale treatments of industrial effluents would certainly require that some scheme for growing or collecting that particular species be established.

In the present work we investigate the possibility of using Arribadas algae to remove lead from the typical effluent of battery manufacturing plants. Arribadas algae consist of several species uprooted from their natural habitats and carried ashore by the action of winds and tides. On the Northeastern coast of Brazil, the algae washed ashore in certain areas are very easy to collect and handle, and occur in amounts large enough to allow consideration of their use as biomass in the treatment of industrial effluents. They also present high capacity for replenishing the stock between tides, probably due to reproduction through spores, thus constituting a low-cost renewable source of adsorption material. Further, since Arribadas algae are naturally occurring waste materials, reaping does not present any ecological problems and also helps to promote tourism-related activities.

Emphasis is given here to an empirical evaluation of the lead-removing capacity of these algae, based on a relatively simple experimental design. No attempt is made, at this stage, to develop a mechanistic model for lead biosorption. Four factors were identified as the most likely to influence the efficiency of the heavy metal adsorption process: intensity of agitation, time of contact, amount of algae and type of pretreatment. The effect of these factors on lead adsorption was studied with factorial designs, to determine the experimental conditions under which lead removal was most effective. Zinc and iron removal efficiencies were also monitored.

A $2^{3}$ factorial design in the first three variables was carried out for each of three pretreatments, the response being heavy metal removal. In a complete two-level design, the value of each controlling variable (or factor) is kept fixed at one of two possible levels and the experiments are done at every possible combination of all levels. With 3 factors, this leads to a minimum of $2^{3}=8$ experiments, hence the name of this specific design.

Traditional methods of optimization, which allow variation of only one factor at a time, all other factors being kept fixed, are adequate when the factors are independent of one another. In the complex systems normally associated with environmental questions, where synergic or antagonistic interactions are common, univariate optimization might yield misleading results ${ }^{9}$. Factorial designs are based on the alternative multivariate approach, in which all factors are considered simultaneously, and on an equal basis. These designs have the considerable advantage of furnishing information concerning not only the individual effect of each factor on the response of interest, but also about the possible interactions between all factors, which often prove very significant ${ }^{10}$.

\section{Experimental}

\section{Biomass preparation}

Arribadas algae were collected at Itamaracá beach (State of Pernambuco, Brazil), washed and dried at $32 \pm 1^{\circ} \mathrm{C}$ for 4 days. They were then divided in three kinds of samples: dried only (D), dried and ground in a knife mill (DG), and dried, ground and sieved in 35mesh sieves (DGS).

\section{Synthetic effluent preparation and analysis}

The solutions for the adsorption experiments were prepared from the $\mathrm{Pb}\left(\mathrm{NO}_{3}\right)_{2}, \mathrm{Zn}\left(\mathrm{NO}_{3}\right)_{2} \cdot 6 \mathrm{H}_{2} \mathrm{O}$ and $\mathrm{Fe}\left(\mathrm{NO}_{3}\right)_{3} \cdot 9 \mathrm{H}_{2} \mathrm{O}$ salts in $0.1 \mathrm{~mol} \mathrm{~L}^{-1}$ nitric acid, with concentrations of $2 \mathrm{mg} \mathrm{L}^{-1}$ for $\mathrm{Zn}$ and $30 \mathrm{mg} \mathrm{L}^{-1}$ for both $\mathrm{Pb}$ and $\mathrm{Fe}$. These values simulate the typical effluent from battery plants as to $\mathrm{pH}$ (equal to 1) and the presence of interfering ions (zinc and iron), and exceed by $50 \%$ the corresponding average concentrations observed in the raw effluent of an actual manufacturing plant located in Northeastern Brazil. Lead, zinc and iron contents were quantified by Inductively Coupled Plasma Atomic Emission Spectrometry (ICP-AES) before and after the experiments were carried out. Removal efficiencies were calculated from the concentration differences.

Determination of solid residue, ash and water contents in algae samples

$1 \mathrm{~g}$ duplicate algae samples were dried at $32 \pm 1{ }^{\circ} \mathrm{C}$ and weighed. Percent weight loss was recorded as the water content at $32 \pm 1{ }^{\circ} \mathrm{C}$. The samples were then heated to constant weight at $105 \pm 1{ }^{\circ} \mathrm{C}$. Accumulated percent weight 
loss relative to the natural material was recorded as the water content at $105 \pm 1{ }^{\circ} \mathrm{C}$. To determine solid residue and ash content the dried samples were calcinated at $600 \pm 1^{\circ} \mathrm{C}$ and then incinerated at $900 \pm 1^{\circ} \mathrm{C}$.

\section{The $2^{3}$ factorial design}

The experimental conditions for the removal experiments are given in Table 1. All experiments were made in duplicate, to obtain an estimate of experimental error, and another experiment was carried out in triplicate at intermediate conditions. In all, therefore, 22 experiments were done, in $100 \mathrm{~mL}$ batches of the synthetic effluent. The ranges initially chosen for factors $\mathbf{W}$ and $\mathbf{T}$ (weight of the algae sample and time of contact) were 0.2-0.6 $\mathrm{g}$ and 1-5 h, respectively. Since lead removal under these conditions remained below $30 \%$, the factor ranges were extended until removal in the $90 \%$ vicinity was reached, resulting in the design of Table 1 . Following the usual convention, the two extreme levels are denoted by minus one (lower level) and plus one (higher level). This, as we shall see, leads to a convenient algorithm to analyze the experimental results.

\section{Results and Discussion}

\section{Solid residue, ash and water contents}

The algae contain on average $89.6 \%$ water, leaving only $10.4 \%$ of dry matter at $105^{\circ} \mathrm{C}$. The solid residue is $8.7 \%$ at $600{ }^{\circ} \mathrm{C}$ and $1.8 \%$ of ashes at $900{ }^{\circ} \mathrm{C}$. Use of biomass dried at $32 \pm 1{ }^{\circ} \mathrm{C}$ is probably advantageous over the other conditions, because the energy requirements are low, and the dried algae keep well and are more easily stored. Also, a $1 \mathrm{~g}$ sample of natural algae is reduced to only $0.12 \mathrm{~g}$ of dry matter.
Table 1. Factor levels for the $2^{3}$ factorial design. Level combinations were applied to samples submitted to each of three pretreatments: (a) dried only (D), (b) dried and ground (DG), and (c) dried, ground and sieved (DGS). Experiments at the lower and higher levels were carried out in duplicate and those at intermediate levels in triplicate. Runs 1 to 8 correspond to all possible combinations of the two extreme levels of the factors. The ninth and tenth are intermediate points. All experiments are run in $100 \mathrm{~mL}$ batch samples of the synthetic effluent.

\begin{tabular}{|c|c|c|c|c|}
\hline \multirow[b]{2}{*}{ Label } & \multirow[b]{2}{*}{ Factors } & \multicolumn{3}{|c|}{ Levels } \\
\hline & & -1 & Intermediate & +1 \\
\hline $\mathbf{A}$ & Agitation & Without & - & With \\
\hline $\mathbf{W}$ & Algae weight (g) & 2 & 3 & 4 \\
\hline $\mathbf{T}$ & Contact time (h) & 3 & 6 & 12 \\
\hline \multirow[b]{2}{*}{ Run } & \multicolumn{4}{|c|}{ Factor levels } \\
\hline & $\mathbf{A}$ & & W & $\mathbf{T}$ \\
\hline 1 & -1 & & -1 & -1 \\
\hline 2 & +1 & & -1 & -1 \\
\hline 3 & -1 & & +1 & -1 \\
\hline 4 & +1 & & +1 & -1 \\
\hline 5 & -1 & & -1 & +1 \\
\hline 6 & +1 & & -1 & +1 \\
\hline 7 & -1 & & +1 & +1 \\
\hline 8 & +1 & & +1 & +1 \\
\hline 9 & -1 & & 0 & -0.5 \\
\hline 10 & +1 & & 0 & -0.5 \\
\hline
\end{tabular}

Removal of heavy metals from solution

\section{Lead removal}

The results obtained using the experimental design of Table 1 for lead removal are given in Table 2. Replicate runs were carried out, to yield an estimate of pure experimental error.

The analysis of a two-level factorial design begins with the calculation of the main effects of all factors and the interactions between them. All effects are calculated as differences between two averages, each average containing half of the experimental responses at the extreme levels of the design ${ }^{10-11}$. With 3 factors, as in Table 2, each average

Table 2. Percent lead removal values $\left(R_{i}\right)$ for the experimental runs specified in Table 1, for algae pretreated in three different ways: just dried (D), dried and ground (DG), and dried, ground and sieved (DGS). Within each series, the experiments were performed in random order. The subscript (1), (2) or (3) identifies genuine replicates. The subscript (av) indicates average of replicate results, which are used to calculate main and interaction effects.

\begin{tabular}{|c|c|c|c|c|c|c|c|c|c|c|c|c|}
\hline \multirow[t]{2}{*}{ Run } & \multicolumn{4}{|c|}{$\mathrm{D}$} & \multicolumn{4}{|c|}{ DG } & \multicolumn{4}{|c|}{ DGS } \\
\hline & $\mathrm{R}_{1}$ & $\mathrm{R}_{2}$ & $\mathrm{R}_{3}$ & $\mathrm{R}_{\mathrm{av}}$ & $\mathrm{R}_{1}$ & $\mathrm{R}_{2}$ & $\mathrm{R}_{3}$ & $\mathrm{R}_{\mathrm{av}}$ & $\mathrm{R}_{1}$ & $\mathrm{R}_{2}$ & $\mathrm{R}_{3}$ & $\mathrm{R}_{\mathrm{av}}$ \\
\hline 1 & 66.86 & 58.58 & - & 62.72 & 54.84 & 72.99 & - & 63.92 & 60.51 & 67.89 & - & 64.20 \\
\hline 2 & 65.84 & 49.24 & - & 57.54 & 60.43 & 64.31 & - & 62.37 & 60.96 & 63.57 & - & 62.27 \\
\hline 3 & 89.95 & 84.79 & - & 87.37 & 87.45 & 99.11 & - & 93.28 & 98.19 & 98.63 & - & 98.41 \\
\hline 4 & 86.09 & 80.07 & - & 83.08 & 95.01 & 98.97 & - & 96.99 & 99.09 & 98.82 & - & 98.96 \\
\hline 5 & 58.28 & 53.27 & - & 55.78 & 54.27 & 65.82 & - & 60.05 & 73.81 & 64.81 & - & 69.31 \\
\hline 6 & 57.41 & 73.86 & - & 65.64 & 54.76 & 66.22 & - & 60.49 & 62.32 & 68.33 & - & 65.33 \\
\hline 7 & 86.47 & 89.97 & - & 88.22 & 95.99 & 99.11 & - & 97.55 & 99.36 & 99.25 & - & 99.31 \\
\hline 8 & 93.84 & 98.71 & - & 96.28 & 95.31 & 98.80 & - & 97.06 & 99.32 & 99.16 & - & 99.24 \\
\hline 9 & 77.79 & 74.19 & 75.94 & 75.97 & 89.02 & 95.14 & 83.49 & 89.22 & 96.42 & 95.43 & 96.98 & 96.28 \\
\hline 10 & 86.58 & 89.20 & 85.08 & 86.95 & 86.39 & 95.38 & 86.79 & 89.52 & 98.29 & 97.51 & 98.79 & 98.20 \\
\hline
\end{tabular}


contains four responses. Each of these responses is an average of duplicate values. The three main effects are simply the differences between the average response at the higher level of the factor in question and the corresponding average at the lower level. In a simple factorial design, the intermediate runs are ignored at this stage, and used only to investigate possible curvatures in the experimental response surface. To obtain the main effects one thus applies to the responses in Table 2 the signs of the corresponding columns in Table 1, performs the algebraic sum, and divides the result by four.

For example, using the $\mathrm{R}_{\mathrm{av}}$ values, the main effect of factor A (agitation) on lead removal by the dried algae is given by

$\mathbf{A}=(1 / 4)[-62.72+57.54-87.37+83.08-55.78+65.64$ $-88.22+96.28-75.97+86.95]=2.1 \%$.

The interaction effects are linear combinations of the form

$$
\frac{1}{4} \sum_{\mathrm{i}}^{\mathrm{n}} \mathrm{a}_{\mathrm{i}} \mathrm{y}_{\mathrm{i}}
$$

where $\mathrm{y}_{\mathrm{i}}$ is the average response in run $i$ and the coefficient $\mathrm{a}_{\mathrm{i}}$ is set equal to plus or minus one, depending on the sign of the product of the columns of the factors involved. For example, to calculate the three-factor interaction AWT, the sign of the response in run number 2 is given by $(\mathbf{A})(\mathbf{W})(\mathbf{T})$ $=(+1)(-1)(-1)=+1$. In all, four interaction effects are determined, three of these being two-factor and one threefactor. All calculated effects are presented in Table 3.

Table 3. Main and interaction effects and their standard errors, calculated from the responses given in Table 3. D, DG and DGS refer to the pretreatments to which the algae samples were submitted. Units are percent lead removal. Statistically significant effects, at the $95 \%$ confidence level, are shown in boldface.

\begin{tabular}{lccc}
\hline Effect & \multicolumn{3}{c}{ Pretreatment } \\
& D & DG & DGS \\
\hline Average & $74.6 \pm 1.4$ & $79.0 \pm 1.6$ & $82.1 \pm 0.7$
\end{tabular}

\section{Main Effects}

$\begin{array}{crrr}\text { A - Agitation (no/yes) } & 2.1 \pm 2.8 & 0.5 \pm 3.2 & -1.3 \pm 1.4 \\ \text { W - Algae Weight (g) } & \mathbf{2 8 . 3} \pm 2.8 & \mathbf{3 4 . 5} \pm 3.2 & \mathbf{3 3 . 7} \pm 1.4 \\ \text { T - Retention time (h) } & 3.8 \pm 2.8 & -0.4 \pm 3.2 & 2.3 \pm 1.4 \\ & & & \\ \text { Two-factor interaction } & & & \\ \text { AW } & -0.2 \pm 2.8 & 1.1 \pm 3.2 & 1.6 \pm 1.4 \\ \text { AT } & \mathbf{6 . 8} \pm 2.8 & -0.6 \pm 3.2 & -0.7 \pm 1.4 \\ \text { WT } & 3.2 \pm 2.8 & 2.5 \pm 3.2 & -1.8 \pm 1.4\end{array}$

Three-factor interaction

\begin{tabular}{llll} 
AW & $-0.7 \pm 2.8$ & $-1.5 \pm 3.2$ & $0.4 \pm 1.4$ \\
\hline
\end{tabular}

Before trying to interpret the physical meaning of the numerical values calculated for the effects, it is necessary to obtain an estimate of the experimental uncertainty associated with them. The usual procedure is to pool the standard deviations of the replicate responses into a single overall estimate of experimental error, $\mathrm{s}_{\mathrm{p}}$. Since each effect is given by a linear combination of independent observations, the variances at each experimental setting can be combined into a single value representing the variance of an effect:

$$
\hat{\mathrm{V}}(\text { effect })=\sum_{\mathrm{i}} \mathrm{a}_{\mathrm{i}}^{2} \mathrm{~s}_{\mathrm{i}}^{2}=\frac{\mathrm{s}_{\mathrm{p}}^{2}}{2} \sum_{\mathrm{i}} \mathrm{a}_{\mathrm{i}}^{2}
$$

where $\mathrm{a}_{\mathrm{i}}= \pm 1 / 4$ is the coefficient of the $i$ th response and $\mathrm{s}_{\mathrm{p}}^{2}$ is an estimate of the pooled variance of that response $\mathrm{e}^{10}$ . The square root of $\hat{\mathrm{V}}($ effect $)$ is the standard error of an effect. Substituting into this equation the responses in Table 2, standard errors of 2.8, 3.2 and $1.4 \%$ are obtained for the dried, dried and ground, and dried, ground and sieved algae, respectively. At the $95 \%$ confidence level, these values imply that only effects with absolute values exceeding $6.2 \%$ for dried, $7.1 \%$ for dried and ground and $3.0 \%$ for dried, ground and sieved algae can be considered statistically significant.

The only significant main effect is the amount of algae $(\mathbf{W})$, irrespective of the pretreatment employed. In the preliminary experiments, when smaller contact times were used, time itself also presented a significant effect, which disappeared with the longer times of Table 1. This is an indication that with these longer times lead removal reaches saturation, that is, the "removal equilibrium" has been attained. Use of agitation, on the other hand, does not seem to have any effect on lead removal, indicating that resistance against ion diffusion in the outer layers of the biosorbant is low. No interaction effects are statistically significant. Although the AT interaction for dried algae is a borderline value at this level of significance, we prefer to consider it as a statistical artifact, since it is an isolated case, absent from the other pretreatments.

The overall conclusion of the factorial analysis, then, is that changing the amount of algae from $2 \mathrm{~g}$ to $4 \mathrm{~g}$ leads to an average increase in lead removal of $28.3 \%$, $34.5 \%$ and $33.7 \%$, respectively, for D, DG, and DGS algae samples. The absence of significant interactions means that these results are not affected by changes in time of contact (over the levels considered in the experiments) or use of agitation. Figure 1 is a traditional and convenient way of visualizing these results. Main effects are differences between average responses on opposing faces of the cube. The effect corresponding to increasing algae weight is perceived as a contrast between the higher lead removal values on the upper face of the cube and those on the lower face. 


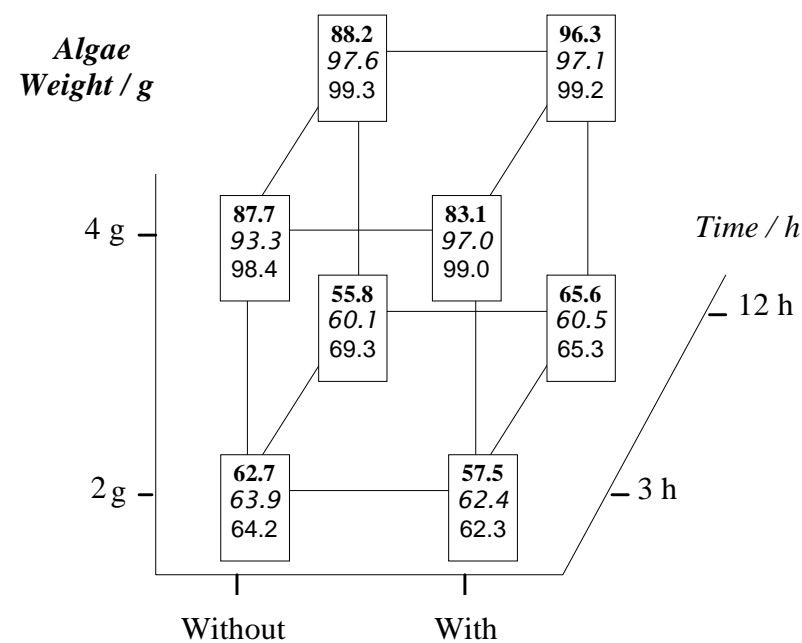

Agitation

Figure 1. Geometrical representation of the results from the $2^{3}$ design on lead removal. Values on top refer to results for dried samples, those in the middle to dried and ground samples, and those at the bottom to dried, ground and sieved samples. Units are percent lead removal. The only significant effect on lead removal - increasing algae weight - is perceived as a contrast of the values on the upper face of the cube with those on the lower face.

In the absence of significant interaction effects, linear models can adequately represent the responses for the three pretreatments:

$$
\hat{y}_{e}=b_{0}+b_{1} x_{\mathrm{A}}
$$

where $b_{0}$ and $b_{1}$ are estimates of the parameters of the model, given respectively by the overall average response and half the W main effect, $\chi_{\mathrm{A}}= \pm 1$ is the weight of the algae sample in coded values, and $\hat{y}_{\mathrm{e}}$ stands for predicted percent lead removal.

When the responses at the intermediate points are included, linear models exhibit lack of fit for all pretreatments. This is indicated by F-test results (at the $95 \%$ confidence level) and by the linear model residual plots (Figure 2).

Fitting a quadratic model, $\hat{y}_{e}=b_{0}+b_{1} x_{\mathrm{A}}+b_{2} x_{A}^{2}$, eliminates the systematic curvature observed in the residual plots for the linear models. Table 4 gives the parameter estimates and their standard errors for the quadratic models. All estimates are statistically significant at the $95 \%$ confidence level. The quadratic term implies that increasing the amount of algae in this range does not lead to a proportionate increase in lead removal, and this in turn suggests that removal equilibrium is being approached. Residual plots for the quadratic model fits are shown in Figure 3. The saturation effect is further confirmed by the decreasing spread of the residuals towards the right side of the second and third plots.
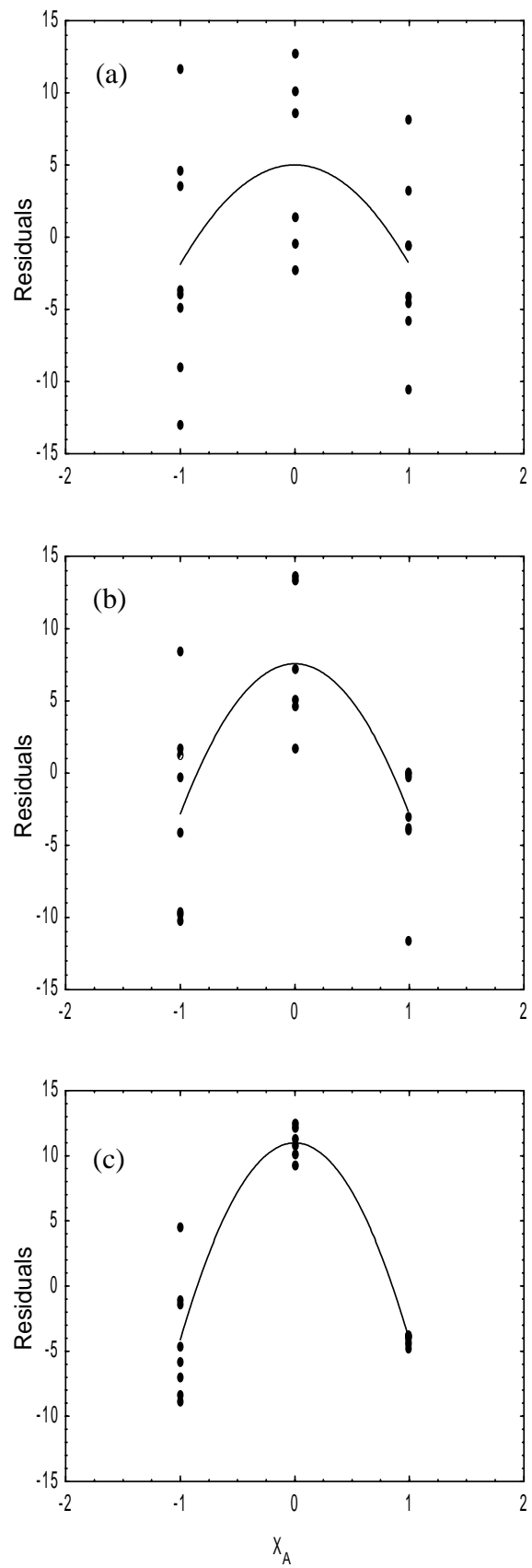

Figure 2. Residual plots for the fit of linear models. All plots present curvature, indicating lack of fit. (a) dried, (b) dried and ground, and (c) dried, ground and sieved.

Table 4. Parameter estimates and standard errors for the fitting of quadratic models to the responses in Table 2. Units are percent lead uptake. Errors are given in parentheses. Notation as in Table 3.

\begin{tabular}{cccc}
\hline Pretreatment & $\mathrm{b}_{\mathrm{o}}$ & $\mathrm{b}_{1}$ & $\mathrm{~b}_{2}$ \\
\hline $\mathrm{D}$ & 81.4 & 14.1 & -6.9 \\
& $( \pm 2.8)$ & $( \pm 1.7)$ & $( \pm 3.2)$ \\
DG & 89.4 & 17.2 & -10.4 \\
& $( \pm 2.2)$ & $( \pm 1.3)$ & $( \pm 2.6)$ \\
DGS & 97.2 & 16.8 & -15.0 \\
& $( \pm 1.1)$ & $( \pm 0.7)$ & $( \pm 1.3)$ \\
\hline
\end{tabular}



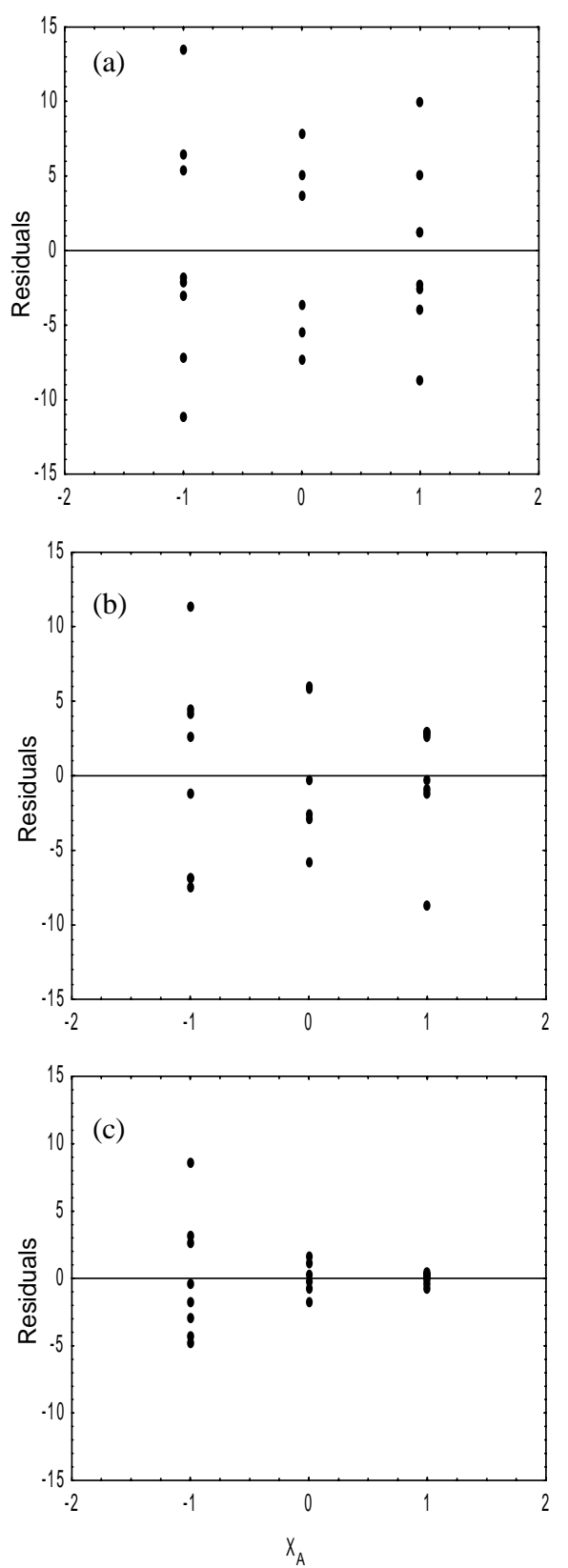

Figure 3. Residual plots for fitting of quadratic models. The second and third plots present smaller spreads at higher weight values, indicating saturation. (a) dried, (b) dried and ground, and (c) dried, ground and sieved.

Figure 1 shows that the Arribadas algae studied here, when dried, ground and sieved and used at the $4 \mathrm{~g}$ level, were able to remove an average of $99 \%$ of the lead from solution. When they are dried and ground but not sieved, the lead removal remains high, but slightly smaller $-96 \%$, on average. Employing algae that were only dried results in an average removal of $89 \%$. For large-scale industrial applications these slightly decreasing performances should be weighed against the increasing costs that grinding and sieving imply.
Zinc and iron removals

Zinc and iron removal results based on the same design used for lead are given in Table 5, and represented geometrically in Figures 4 and 5. Analysis is done in the same fashion.

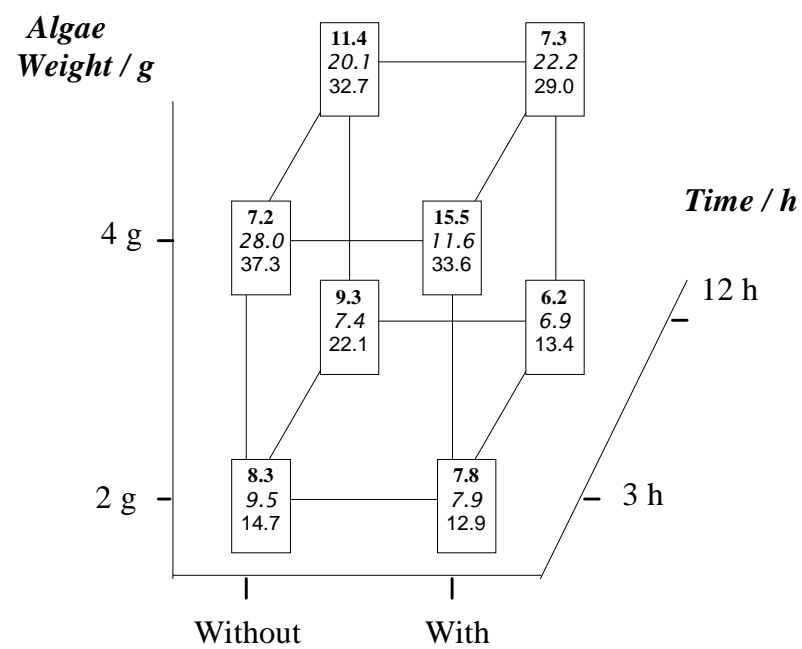

Figure 4. Geometrical representation of the results from the $2^{3}$ design on zinc removal. Notation as in Figure 1.

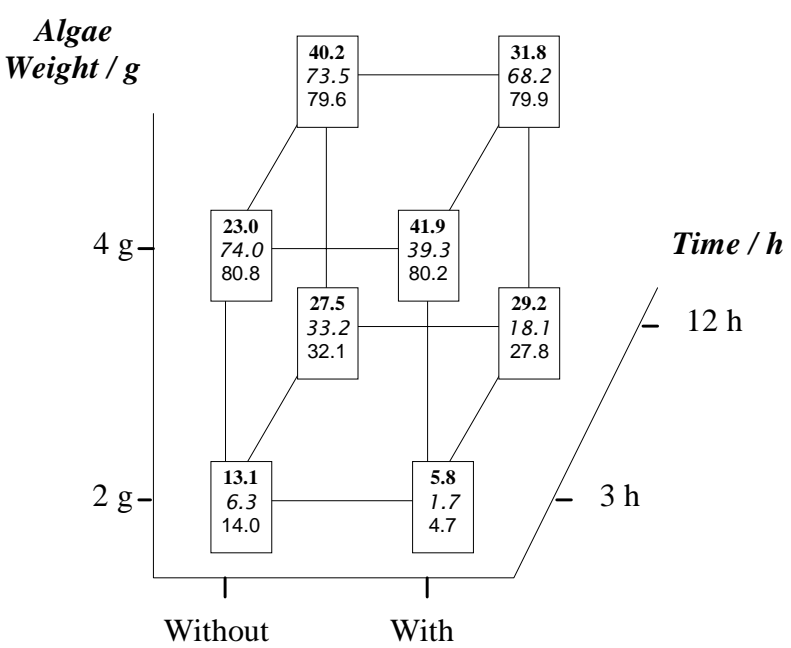

\section{Agitation}

Figure 5. Geometrical representation of the results from the $2^{3}$ design on iron removal. Notation as in Figure 1.

For zinc removal, the effect pattern is quite similar to the one observed for lead, but the responses are much smaller. Only the main effect corresponding to the size of the algae sample $(\mathbf{W})$ is significant, and only when the sample is at least ground. For D samples, once again there is a marginally significant interaction value for contact time and agitation. The meaning of this (possible) interaction 
Table 5. Main and interaction effects for zinc and iron removal. Notation as in Table 4. Statistically significant effects at $95 \%$ confidence level, are shown in boldface.

\begin{tabular}{|c|c|c|c|c|c|c|}
\hline \multirow[t]{3}{*}{ Effect } & \multicolumn{6}{|c|}{ Pretreatment } \\
\hline & \multicolumn{2}{|c|}{$\mathrm{D}$} & \multicolumn{2}{|c|}{ DG } & \multicolumn{2}{|c|}{ DGS } \\
\hline & Zinc & Iron & Zinc & Iron & Zinc & Iron \\
\hline Average & $9.1 \pm 0.7$ & $26.6 \pm 1.0$ & $15.3 \pm 1.4$ & $39.3 \pm 1.2$ & $24.5 \pm 1.6$ & $49.9 \pm 2.1$ \\
\hline \multicolumn{7}{|l|}{ Main Effects } \\
\hline A - Agitation (no/yes) & $0.1 \pm 1.2$ & $1.2 \pm 2.0$ & $-6.4 \pm 2.8$ & $\mathbf{- 1 4 . 9} \pm 2.5$ & $-4.5 \pm 3.2$ & $-3.7 \pm 4.2$ \\
\hline W - Algae Weight (g) & $2.5 \pm 1.2$ & $15.3 \pm 2.0$ & $\mathbf{1 4 . 8} \pm 2.8$ & $48.9 \pm 2.5$ & $\mathbf{1 7 . 4} \pm 3.2$ & $\mathbf{6 0 . 5} \pm 4.2$ \\
\hline $\mathbf{T}$ - Retention time (h) & $1.2 \pm 1.2$ & $11.2 \pm 2.0$ & $-2.2 \pm 2.8$ & $17.9 \pm 2.5$ & $0.4 \pm 3.2$ & $9.9 \pm 4.2$ \\
\hline \multicolumn{7}{|l|}{ Two-factor interaction } \\
\hline AW & $1.9 \pm 1.2$ & $4.0 \pm 2.0$ & $-5.3 \pm 2.8$ & $-5.0 \pm 2.5$ & $0.8 \pm 3.2$ & $3.3 \pm 4.2$ \\
\hline AT & $\mathbf{3 . 8} \pm 1.2$ & $4.5 \pm 2.0$ & $-2.6 \pm 2.8$ & $-4.7 \pm 2.5$ & $1.7 \pm 3.2$ & $-1.5 \pm 4.2$ \\
\hline WT & $0.9 \pm 1.2$ & $7.7 \pm 2.0$ & $-3.7 \pm 2.8$ & $3.7 \pm 2.5$ & $4.3 \pm 3.2$ & $10.7 \pm 4.2$ \\
\hline \multicolumn{7}{|l|}{ Three-factor interaction } \\
\hline AWT & $2.5 \pm 1.2$ & $9.1 \pm 2.0$ & $-2.1 \pm 2.8$ & $-\mathbf{9 . 9} \pm 2.5$ & $-1.7 \pm 3.2$ & $1.0 \pm 4.2$ \\
\hline
\end{tabular}

can be seen in Figure 4. When time of contact increases from $3 \mathrm{~h}$ to $12 \mathrm{~h}$, the average zinc removal under agitation decreases by $4.9 \%$, suggesting that the adsorbed metal is starting to desorb. In the absence of agitation, the time effect $(+1.6 \%)$ is indistinguishable from error. Overall, zinc removal is less efficient than lead removal, and the kind of pretreatment becomes more important. Even using $4 \mathrm{~g}$ of algae, average zinc removal is only $20 \%$ when the sample is dried and ground, and rises to $33 \%$ when it is also sieved. With D samples, average zinc removal falls to only $10 \%$, and it does not appear to depend on the levels of any of the three factors. As these values themselves suggest, the $\mathbf{W}$ main effects are also smaller: $+2.5 \%$ (D), $+14.8 \%$ (DG) and $+17.4 \%$ (DGS).

For iron removal the patterns are more complex, and the effects less clear-cut. For D samples, there are two significant main effects, $\mathbf{W}$ and $\mathbf{T}$, and two significant interactions, WT and AWT. For DG samples, the significant effects are A, W, T and AWT. For DGS samples, the only significant effect is due to sample weight $(\mathbf{W})$. These results are best interpreted by referring to the cube in Figure 5 .

For DGS samples, increasing the amount of algae from $2 \mathrm{~g}$ to $4 \mathrm{~g}$ produces a dramatic rise in average iron removal (from $20 \%$ to $80 \%$ ), and this does not depend significantly on the other two factors. The same weight effect is observed for the other two pretreatments, but is less pronounced and depends on the levels of agitation and contact time.

Longer times generally increase iron removal, but this effect is more pronounced with $2 \mathrm{~g}$ samples. With $4 \mathrm{~g}$ it is nonexistent for DGS samples (and also for DG samples without agitation), indicating that saturation has been reached.

The effect of agitation is the hardest to analyze. For $4 \mathrm{~g}$ samples of D algae, for example, introducing agitation increases removal with $3 \mathrm{~h}$ contact but the effect is reversed when the time is increased to $12 \mathrm{~h}$. If $2 \mathrm{~g}$ samples are used, agitation reduces removal at $3 \mathrm{~h}$, and shows no effect at $12 \mathrm{~h}$. Similar variations are observed for the other treatments.

The type of pretreatment, as in zinc, also influences the extent of iron removal. The largest removal values (80\%) occur with $4 \mathrm{~g}$ of DGS samples. For DG and D samples, maximum iron removals are $74 \%$ and $42 \%$, respectively.

\section{Conclusions}

The results of the $2^{3}$ design show that naturally occurring Arribadas algae are able remove up to $99 \%$ lead from a synthetic solution simulating a typical effluent from battery manufacturing processes, when $4 \mathrm{~g}$ of dried, ground and sieved samples are added to a $100 \mathrm{~mL}$ batch solution. The average lead removal for dried and ground samples is $96 \%$, and for dried samples is $89 \%$. Since no significant effects were observed for the time of contact or the use of agitation, it is less expensive to carry out the adsorption process at the shorter time (3h), without agitation. It is worth noticing that the experiments were done at a starting $\mathrm{pH}$ value of 1 , which is unfavorable to adsorption, and in the presence of interfering ions. Under less stringent conditions, we would expect the process to perform better. It was observed, besides, that in the bio-interaction process $\mathrm{Pb}, \mathrm{Fe}, \mathrm{Zn}$ e $\mathrm{H}^{+}$ions in solution are exchanged with alkaline ( $\mathrm{Na}$ e $\mathrm{K}$ ) and alkalineearth ions ( $\mathrm{Ca}$ e $\mathrm{Mg}$ ) present in the algae. As a consequence, the final $\mathrm{pH}$ value is about 5 , the minimum value allowed by Brazilian legislation for effluents discharged on water bodies ${ }^{12}$. Adding a neutralizing agent before discharge would then be a minor concern.

Zinc and iron removal maximum values, $33 \%$ and $80 \%$, respectively, were also obtained with $4 \mathrm{~g}$ of dried, ground and sieved algae. The algae based adsorption process 
suggested here is a promising alternative for the final treatment of lead-containing industrial effluents.

\section{Acknowledgements}

The authors gratefully acknowledge partial financial support from the government agencies BN, FACEPE and CNPq.

\section{References}

1. Brauckmann, B. M. In Biosorpion of heavy metals, Ed.; Volesky, B.; CRC Press; Florida, 1990, p 51.

2. Gonçalves, M. M. M.; Costa, A. C. A.; Mesquita, L. M. S. In XVI Encontro Nacional de Tratamento de Minérios e Hidrometalurgia. 1995, II, 532.

3. Williams, C. J.; Aderhold, D.; Edyvean, R. G. Water Res. 1998, 32, 216.
4. Costa, A. C. A.; França, F. P. Separation Science and Technology 1996, 31, 2373.

5. Crist, R. H.; Martin, J. K. R.; Guptill, P. W.; Eslinger, J. M.; Crist, D. R. Environ. Sci. Technol. 1990, 24, 237.

6. Kuyucak, N.; Volesky, B. Biotechnol. and Bioeng. 1989, 33, 809.

7. Matheickal, J. T. ; Yu, Q. Water Sci. Technol. 1996, 34, 1.

8. Volesky, B.; Kratochvil, D. Water Res. 1998, 32, 2760.

9. Eiras, S. P.; Andrade, J. C. Quim. Nova 1997, 19, 24.

10. Box, G. E. P.; Hunter, W. G.; Hunter, J. S. Statistics for Experimenters; Ed.; John Wiley \& Sons; New York, 1978, p 655.

11. Barros Neto, B.; Scarmínio, I. S.; Bruns, R. E. Planejamento e Otimização de Experimentos, Ed.; UNICAMP; São Paulo, 1996, p 299.

12. Conselho Nacional do Meio Ambiente. Resoluções do CONAMA; 1984/91 - Resolução CONAMA no. 20 Art. 21. 4a Ed.; IBAMA, Brasília, 1992, p 245.

Received: September 12, 2000 Published on the web: May 21, 2001 